NASA Technical Memorandum 83277 NASA-TM-83277 19820017342

\title{
THRUST-INDUCED EFFECTS ON LOW-SPEED TH. AERODYNAMICS OF FIGHTER AIRCRAFT
}

Daniel W. Banks, P. Frank Quinto, and John W. Paulson, Jr.

May 1982

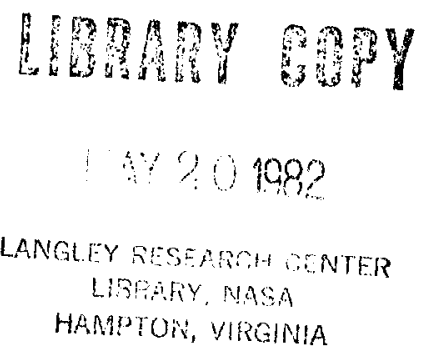

National Aeronautics and

Space Administration

LISGRFY NASA

Langley Research Center Hampton, Virginia 23665 



\section{SUMMARY}

A brief review of takeoff and landing requirements for the next generation of fighter aircraft indicates that improvement in lift performance and thrust reversing capability will be needed if Short Takeoff and Landing (STOL) operations are to be feasible. NASA Langley has conducted wind-tunnel investigations of several fighter configurations to determine the effects of both thrust vectoring and spanwise blowing. The investigations included: a NASA powered wing-canard configuration which had two-dimensional vectored nozzles at the wing trailing edge; a General Dynamics powered vectored-engine-over (VEO) wing configuration which used two-dimensional main nozzles along with spanwise blowing on the wing upper surface over deflected flaps; and a Boeing supersonic cruise configuration which used two-dimensional vectoring nozzles below the wing along with a directlift jet in the fuselage nose for trim. Since these results have been published elsewhere, these findings are only reviewed briefly in this paper. A recent joint NASA/Grumman Aerospace Corporation/U.S. Air Force Wright Aeronautical Laboratory wind-tunnel investigation was conducted to examine the effects of spanwise blowing on the trailing-edge flap system. This application contrasts with the more familiar method of spanwise blowing near the wing leading edge. Another joint program among NASA/McDonnell Aircraft Company/U.S. Air Force Wright Aeronautical Laboratory investigated the effects of reverse thrust on the low-speed aerodynamics of an F-15 configuration. The F-15 model was fitted with a rotating vane thrust reverser concept which could simulate both in-flight reversing for approach and landing or full reversing for ground roll reduction. The significant results of these two joint programs are reported in this paper.

\section{INTRODUCTION}

With the recent interest in STOL performance for fighter aircraft, the NASA Langley Research Center has undertaken a program to help define and develop the technologies required for low-speed flight of advanced fighter/attack configurations with emphasis on STOL operations. This effort includes research on advanced high-lift systems using mechanical flaps; thrust vectoring; thrustinduced effects; methods of obtaining longitudinal trim when using thrust vectoring; and reverse thrust for decreased ground rolls.

The need for these technologies is shown in figures 1, 2, and 3. Ground roll distances for both takeoff and landing (fig. 1) indicate that present day fighter aircraft can become airborne in relatively short distances (300-375 $\mathrm{m}$ (985-1230 ft)), but they have little or no short field capability for landing as indicated by ground roll distances of about $800 \mathrm{~m}(2625 \mathrm{ft})$. One potential solution to balance the field lengths (i.e. have equal takeoff and landing ground rolls) is to incorporate an efficient thrust reverser into the airplane design (fig. 2). In figure 2, it can be seen that if maximum wheel braking and reverse thrust $(50$ percent of military power) can be employed at wheel touchdown, after a no flare landing, then landing ground rolls on the order of 300 to $395 \mathrm{~m}(985-1230 \mathrm{ft})$ can be obtained at approach lift coefficients of about 1.0. It should be noted that this level of lift will not be a significant increase from present day approach lift coefficients. However, if the ground roll requirement becomes less than 305 $\mathrm{m}(1000 \mathrm{ft})$, then the approach lift coefficient must increase dramatically. In figure 3 , a slightly conservative approach (i.e. wheel braking and reverse thrust 
I second after wheel touchdown, again after a no flare landing) still yields a landing ground roll of $305 \mathrm{~m}(1000 \mathrm{ft})$ at only modest increases in present approach lift coefficients. However, there can be a vast difference in the performance required of an aircraft if it is to land in only $305 \mathrm{~m}$ (1000 ft) of usable runway rather than have $305 \mathrm{~m}$ (1000 ft) of actual ground roll. If touchdown dispersion, reduced braking distances (i.e. wet or icy runway), and a 1 second piloting delay are to be included in the $305 \mathrm{~m}(1000 \mathrm{ft})$ of usable runway (shown schematically by the shaded bar in fig. 3), then the aircraft must be capable of operations from a $150 \mathrm{~m}(500 \mathrm{ft})$ ground roll which require approach lift coefficients on the order of 2.5. This level of lift coefficient can be obtained on conventional fighter-type configurations only through the use of some form of powered lift.

SYMBOLS
a
acceleration, $\mathrm{m} / \mathrm{sec}^{2}$ (ft/ $\mathrm{sec}^{2}$ )
b wing span, $m$ (ft)
c wing mean aerodynamic chord, m (ft)
$C_{D}$ drag coefficient, Drag/qS
$C_{D, 0}$ minimum drag coefficient
$C_{L} \quad$ lift coefficient, Lift/qS
$\mathrm{C}_{\mathrm{L}, 0} \quad$ lift coefficient at $\alpha=0^{\circ}$
$\mathrm{C}_{\mathrm{L}_{\alpha}} \quad$ lift-curve slope, $\partial \mathrm{C}_{\mathrm{L}} / \partial \alpha$
$C_{m}$ pitching-moment coefficient, pitching-moment/gSc
$\mathrm{C}_{\mathrm{m}, \mathrm{O}}$ pitching-moment coefficient at zero lift
$\mathrm{C}_{\mathrm{m}_{\alpha}} \quad$ pitching-moment stability derivative, $\partial \mathrm{C}_{\mathrm{m}} / \partial \alpha$
$\mathrm{C}_{\mathrm{m}_{\mathrm{HT}}}$ horizontal tail effectiveness, $\partial \mathrm{C}_{\mathrm{m}} / \partial \delta_{\mathrm{HT}}$
$C_{n} \quad$ yawing-moment coefficient, Yawing moment/qsb
$C_{n_{\beta}}$ directional stability derivative, $\partial C_{n} / \partial \beta$
$C_{n_{\delta_{R}}} \quad$ rudder effectiveness, $\partial C_{n} / \partial \delta_{R}$
$\mathrm{C}_{\mathrm{T}}$ static thrust coefficient, static thrust/gs
$c_{\mu} \quad$ ideal thrust coefficient, Ideal thrust/qs
$\Delta \mathrm{C}_{\mathrm{L}}, \Gamma$ thrust-induced increment in lift coefficient, $\mathrm{C}_{\mathrm{J}} \mathrm{C}_{\mathrm{T} \geqslant 0}-\mathrm{C}_{\mathrm{T}} \sin \left(\alpha+\theta_{\mathrm{j}}\right)-\mathrm{C}_{\mathrm{L}} \mathrm{C}_{\mathrm{T}=0}$ 


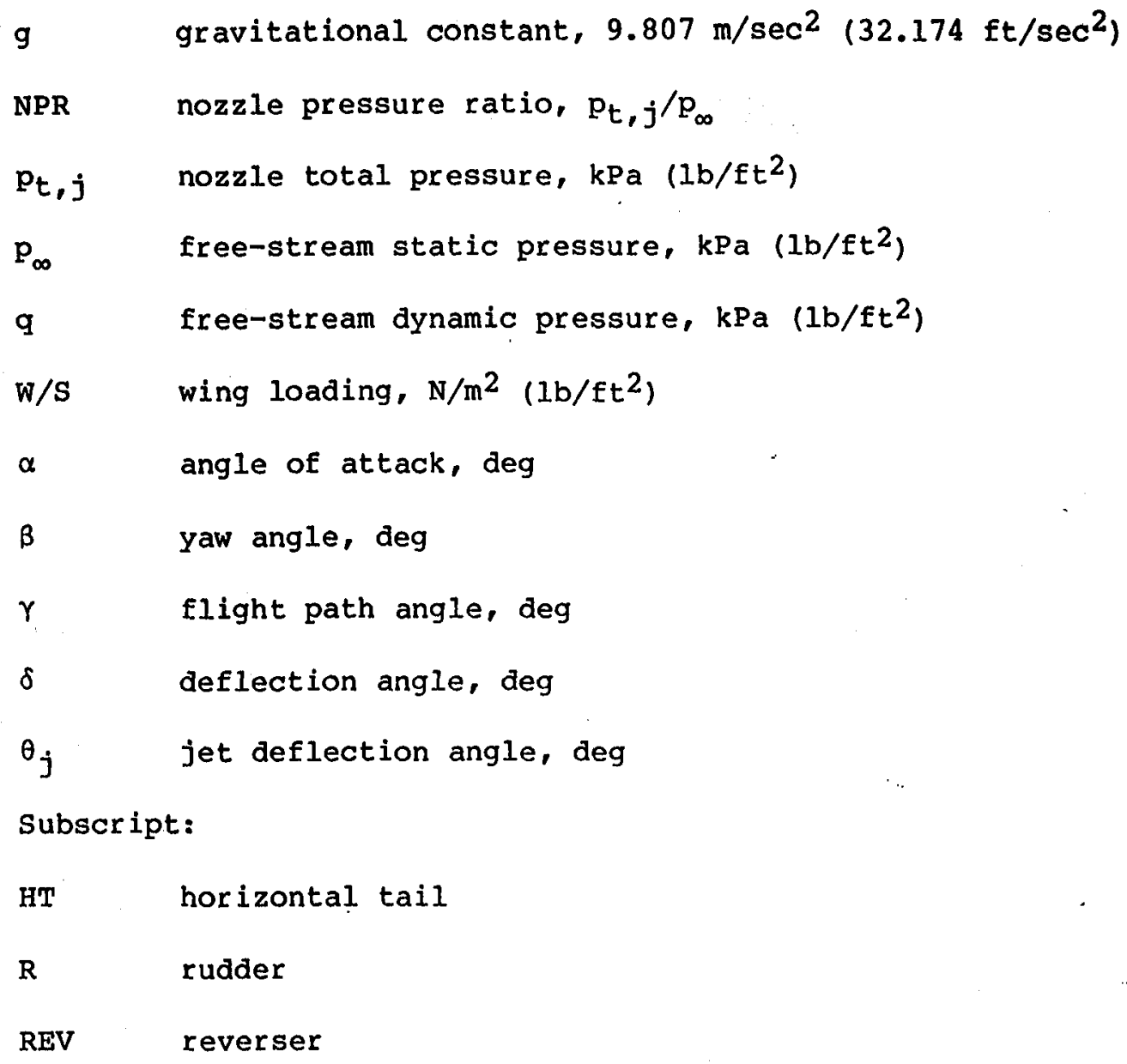

NASA Langley has conducted several wind-tunnel investigations on three separate advanced fighter configurations in an effort to define the aerodynamic effects of various forms of vectored thrust. One configuration (shown in fig. 4) was a close-coupled wing-canard model which used vectoring two-dimensional nozzles located at the wing trailing edge near the wing root. Results obtained with this model have been reported in several reports (refs. 1 to 5 ), and only general summary comments will be included in this paper. This configuration could obtain the 
values of $C_{L}$ and $C_{D}$ required for takeoff or landing by using vectored thrust. However, when either high $C_{T}$ or large nozzle deflection were used for thrust vectoring, longitudinal trim could not be obtained with the canard. Moreover, the induced lift increments due to thrust were small and appeared to be due to boundary-layer control (BLC) rather than induced circulation. Analysis did indicate that the canard could provide sufficient pitching moment for control if an alternate method of obtaining longitudinal trim could be found. Limited data obtained on the configuration with a direct lift nose jet showed that 8 to 10 percent of total thrust would be required to trim the pitching moments produced by the flaps and vectored thrust during takeoff and landing (see ref. 3).

Another STOL concept studied at Langley was the General Dynamics/Ft. Worth Division Vectored-Engine-Over,wing (VEO wing) shown in figure 5. This VEO wing concept used a nozzle located above the wing forward of the trailing-edge flap. In addition to the main chordwise nozzles, the model had spanwise blowing ports located on the wing upper surface at approximately $0.25 \mathrm{c}$. This configuration, which obtained vectoring by varying the nozzle ramp angle and the trailing-edge flap angle, has been reported in several reports (refs. 4 to 10). As was the case for the previous configuration, the use of vector angle and $C_{T}$ produced the values of $C_{L}$ and $C_{D}$ required for takeoff and landing performance; however, longitudinal pitch trim again could not be maintained with the canard alone. The induced effects from the chordwise nozzles were small and appeared to be due to BLC rather than induced circulation. The induced effects from the spanwise blowing were much larger and appeared to be due to a combination of BLC and induced circulation rather than leading-edge vortex enhancement. Analysis indicated that an extended "beaver tail" tail surface and rather high static instability would allow longitudinal trim at high angles of attack. However, control authority was very limited at that condition (ref. 8).

A third configuration, shown in figure 6 , was a supersonic cruise configuration developed by Boeing using under the wing vectoring nozzles and a direct lift nose jet to obtain longitudinal trim when using thrust vectoring. As in the previous two configurations, $C_{L}$ and $C_{D}$ could be obtained with vectored thrust, and the induced effects were rather small (see refs. 4 and 5). However, the nose jet provided trim at nozzle vector angles up to $30^{\circ}$ while leaving the canard available for longitudinal control.

With this background in power induced effects, NASA Langley is currently involved in several joint programs to investigate other means of generating high lift, obtaining longitudinal trim and developing a knowledge of reverse thrust effects. The remainder of this paper will discuss two recent wind-tunnel studies: (1) a joint NASA/Grumman Aerospace Corporation/U.S. Air Force Wright Aeronautical Laboratory (AFWAL) investigation of the effects of spanwise blowing on a trailingedge flap system; and (2) a joint NASA/MCDonnell Aircraft Company (MACAIR)/AFWAL investigation of the effect of reverse thrust on the low-speed aerodynamics of an F-15 configuration.

\section{Effects of Spanwise Blowing on the Trailing-Edge Flap}

Grumman is under contract with AFWAL to develop advanced exhaust nozzles for survivable STOL aircraft. This effort is being supported by NASA through windtunnel testing and analysis. The baseline Grumman configuration is shown in 
figure 7, and it was proposed that a method of generating increased lift might be to blow exhaust air spanwise along the flap either above or below the wing. Since there was remarkable similiarity between the planforms of the Grumman configuration and the NASA close-coupled wing-canard configuration discussed earlier, it was decided that the NASA model could be modified to incorporate the Grumman nacelle, primary nozzles, spanwise blowing nozzles, and trailing-edge flap systems. The assembled model is shown in figure 8 , and the new hardware along with the modified NASA wing is shown in figure 9. A photograph of the under-thewing spanwise blowing nozzle (cascade), shown in figure 10, indicates the location of the cascade below and forward of the trailing-edge flap. The cascades were intended to divert a large (20 t6 60 percent) portion of exhaust mass flow in the spanwise direction at three vector angles (i.e. $0^{\circ}$, perpendicular to nacelle center line; $30^{\circ}$, parallel to flap hinge line; and $-30^{\circ}$, blowing forward). It was anticipated that the spanwise cascade exhaust flow would mix with the free stream, turn downstream and be turned by the trailing-edge flap in a manner not unlike an externally blown flap. A photograph of the above-the-wing spanwise blowing nozzle (port), shown in figure 1l, indicates the port location above and just aft of the upper surface of the flap. The ports were intended to divert a small ( 5 to 10 percent) portion of the exhaust mass flow in the spanwise direction at three vector angles (i.e. $30^{\circ}$ parallel to flap hinge line and $45^{\circ}$ and $60^{\circ}$ or $15^{\circ}$ and $30^{\circ}$, aft of the hinge line). The spanwise port exhaust flow would set up a vortex on the upper surface of the flap which would help maintain attached flow on the highly deflected flap.

During the test all cascades and ports were tested in a screening process to determine the most effective configurations at nominal approach angles of attack (i.e. $12^{\circ}, 14^{\circ}$, and $16^{\circ}$ ), and these configurations were then investigated over more complete angle-of-attack ranges. This screening process is omitted for this paper and a discussion of two cascades and one port will follow. The definition for a most effective configuration was the largest induced lift for a given mass flow; that is, if two cascades generated the same $\Delta C_{L}, \Gamma$ then the cascade with the smallest mass flow would be investigated over a complete angle-of-attack range. A similar rationale was used to determine the most effective port.

An example of the $\Delta \mathrm{C}_{\mathrm{L}, \Gamma}$ for a cascade is shown in figure 12. Data are shown for the primary nozzle alone, cascade alone and primary nozzle plus cascade. This cascade was intended to divert 60 percent of exhaust mass flow parallel to the flap hinge line. It can be seen that the primary nozzle at $\delta_{\mathrm{N}}=45^{\circ}$ gives a constant $\Delta C_{L_{1}, \Gamma} \simeq 0.1$ at all $C_{\mu} \geqslant 0.4$. The induced lift from the cascade alone is on the order of 0.15 and is constant above $C_{\mu} \simeq 0.8$. The induced lift for the combination of $45^{\circ}$ primary nozzle deflection and $30^{\circ}$ cascade has a maximum of about 0.43 which is considerably greater than the numerical addition of the primary plus the cascade indicating a substantial beneficial interference. The mechanism of this interference is being investigated further, but at present, is unknown. At the maximum $\Delta C_{L, \Gamma} \simeq 0.43$, the total lift coefficient for the configuration was $C_{L}=2.18$. Therefore, the thrust-induced lift was about 20 percent of the total lift. Compared to the induced-lift increments published in references 4 and 5, this rather substantial amount of induced lift indicates that the spanwise blowing is distributing the flow over the entire wing trailing edge. This conclusion was confirmed in the oil flow studies done during the test as shown in figure 13. The trace of the spanwise flow is clearly shown out to the 
wing tip. The inboard flap, however, does not appear to be affected as the spanwise flow penetrates outboard before expanding and turning to impinge on the outboard flap.

The induced lift for an alternate cascade configuration which also diverted 60 percent of exhaust flow, but which exited normal to the nacelle rather than parallel to the flap hinge line is shown in figure 14. The oil flow for this condition is shown in figure 15. Induced lift losses were experienced as the spanwise jet blew off the wing tip and never turned to impinge on the trailing-edge flap.

The induced lift increment for a port is shown in figure 16 and the oil flow in figure 17. This port diverted 10 percent of exhaust mass flow parallel to the flap hinge line. The primary nozzle with $\delta_{N}$ of $45^{\circ}$ produced a constant $\Delta \mathrm{C}_{\mathrm{L}, \Gamma} \simeq 0.1$. The port alone produced $\Delta \mathrm{C}_{\mathrm{L}, \Gamma}$ up to 0.2 , and the combined port and primary nozzle are only slightly greater than the numerical sum of the primary plus port indicating minimal interference between the flows on the upper and lower surfaces. Again, the trace of the spanwise jet is clearly seen in the flow photograph. It passes over the inboard and outboard flap and beneath the end of the undeflected wing tip.

As mentioned earlier, the cascade parallel to the flap hinge line produced about 20 percent of the total configuration lift through induced effects. To assess the usefulness of this increment, the total configuration longitudinal aerodynamics are presented in figure 18. It is seen here that although $C_{L}$ and $C_{D}$ are appropriate for a landing condition (i.e. $C_{\mathrm{L}} \simeq 2.4$ at $\alpha=16^{\circ}$ with $c_{\mu} \simeq 1.13$ and $C_{L} / C_{D}$ yielding $a \simeq-3^{\circ}$ ) the pitching-moment coefficient is extremely nose down and would preclude the possibility of trimming the configuration at this condition. Thus, as with most powered lift systems, it is not $\mathrm{C}_{\mathrm{L}}$ and $C_{D}$ that present problems but obtaining pitch trim that remains the limiting factor in the usefulness of these concepts.

\section{F-15 With Rotating Vane Thrust Reversers}

MACAIR, NASA Langley, AFWAL, and Pratt and Whitney are involved in a joint research project to determine the effects of reverse thrust on the low-speed aerodynamics of fighter aircraft. There are problems associated with using reverse thrust on any aircraft; however, when the relatively high approach speeds for Eighter aircraft are combined with the relatively short runways that the Air Force STOL requirements are projecting, a very significant problem area is identified the engines must be at or near military power on approach. This requirement arises because the time it takes for an engine to spool up from near flight idle to military power is about the same time increment required for the entire short landing sequence.

One promising method of spoiling thrust on approach and providing full reverse thrust on landing is the rotating vane concept shown in figure 19. The rotating vanes can be deflected at an angle (nozzle vector angle) that permits the aircraft to maintain the thrust vector needed for approach while the engine is maintaining military power. The excess thrust is spoiled by symmetric deflections of the upper and lower vanes. Approach thrust can be varied by changing the 
nozzle vector angle rather than by variation in throttle setting. Once the aircraft has made contact with the ground, the vanes can be quickly (on the order of 1 second) rotated forward to a full reverse vector angle of about $120^{\circ}$ to $130^{\circ}$, and military power reverse thrust is available shortly after touchdown. If this rotation were to be initiated, say, 1 second before touchdown, it may be possible to have full reverse thrust at wheel contact. Furthermore, if needed, the vanes can be deflected independently to provide a powerful pitch control capability to augment the horizontal tail.

An F-15 model has been tested in the 4- by 7-Meter Tunnel, and an installation photograph is shown in figure 20. This model was equipped with a rotating vane thrust reverser (see fig. 21). The longitudinal aerodynamic characteristics of this installation are presented in figure 22. The data of figure 22 show that at military power settings (NPR $=2.64$ ), the lift-curve slope relative to the baseline data is basically unchanged at nozzle vector angles from $50^{\circ}$ to $70^{\circ}$ with a slight negative shift in $\mathrm{C}_{\mathrm{L}, \mathrm{O}}$ at $70^{\circ} / 70^{\circ}$. At an unsymmetric vector angle of $90^{\circ} / 50^{\circ}$, there is, of course, a substantial negative shift in $\mathrm{C}_{\mathrm{L}} \mathrm{o}^{\circ}$ however, $\mathrm{C}_{\mathrm{L}_{\alpha}}$ is basically unaffected. The lift curve is reduced at the $130^{\circ}$ nozzle vector angle for full reverse thrust in ground effect. The primary effect of nozzle vector angle on $c_{m}$ appears to be increases in $c_{m, o}$ at increasing vector angles, especially for the $90^{\circ} / 50^{\circ}$ which produces large nose-up moments. There are some changes in the slope of the pitching-moment curve $\left(C_{\mathrm{m}_{\alpha}}\right)$ below $\alpha=12^{\circ}$. However, it is unclear whether or not this loss of stability is due to an installation problem (i.e., an interference between the large post mount and the horizontal tail) or is directly due to the exhaust plume. The drag polars are shifted by the vector component of thrust as the nozzle vector angle is increased. The $90^{\circ} / 50^{\circ}$ configuration should produce about the same thrust as the $70^{\circ} / 70^{\circ}$ assuming each nozzle is passing equal mass flow. Since it produces considerably less thrust, it appears that more of the mass flow is exiting out the top vane at $90^{\circ}$ than the bottom vane at $50^{\circ}$. The large $C_{D}$ produced for the $130^{\circ} / 130^{\circ}$ nozzle vector angle is equivalent to 53 percent of military thrust, which is consistent with target values of approximately 50 to 60 percent of military thrust. It should be noted that the data for the $130^{\circ} / 130^{\circ}$ nozzle were obtained in ground effect; whereas, the previous examples of approach partial reverse thrust were obtained out-ofground effect. From the flight path lines on the figure, it appears that a nozzle vector angle of about $60^{\circ} / 60^{\circ}$ will be required if a $\gamma=-4^{\circ}$ approach were to be flown at the nominal F-15 approach angle of attack of $12^{\circ}$. This would probably be a lower limit for approach angle, and the upper limit of $-7^{\circ}$ or $-8^{\circ}$ can be achieved with a nozzle vector angle of $70^{\circ} / 70^{\circ}$. Therefore, results from the $70^{\circ} / 70^{\circ}$ configuration will be used to show directional stability, rudder power, and horizontal tail power.

The horizontal tail power $\partial \mathrm{C}_{\mathrm{m}} / \partial \delta_{\mathrm{HT}}$ shown in figure 23 for the baseline F-15 with flight idle (NPR $=1.35$ ) thrust setting is about constant with angle of attack. The values of $\partial \mathrm{C}_{\mathrm{m}} / \partial \delta_{\mathrm{HT}}$ for the $70^{\circ} / 70^{\circ}$ configuration at military power settings increases from 0 at $-4^{\circ}$ angle of attack to about a constant -0.014 above $\alpha=12^{\circ}$. This level is about 50 percent greater than the baseline. The reduction in $\partial c_{m} / \partial \delta_{H T}$ and loss of longitudinal stability mentioned previously at low angles of attack are usually attributed to a reduction in dynamic pressure at the tail due to the effect of the exhaust jet. However, as mentioned earlier, it is 
unclear as to whether or not this is an installation problem or a direct effect of the exhaust plume.

The rudder power and directional stability are presented in figure 24, and there is essentially no change in rudder power from the baseline F-15 to the $70^{\circ} / 70^{\circ}$ configuration. There is a modest increase in directional stability throughout the angle-of-attack range for the $70^{\circ} / 70^{\circ}$ configuration when compared to the baseline F-15. The reduction in $\mathrm{C}_{\mathrm{n}_{\beta}}$ at high $\alpha$ for the baseline $\mathrm{F}-15$ is also apparent in the $70^{\circ} / 70^{\circ}$ data. Overall, it would appear that the $70^{\circ} / 70^{\circ}$ nozzle vector angle at military power setting would be a viable configuration for in-flight thrust reversing for approach.

Once the airplane is on the ground, the $130^{\circ}$ nozzle vector angle appears to offer the needed reverse thrust performance for reduced ground roll. A comparison of maximum performance (i.e. minimum distance) landing ground roll for a baseline F-15, and the $130^{\circ} / 130^{\circ}$ nozzle vector angle is shown in figure 25 . Assumptions for baseline ground roll were: idle thrust and maximum wheel braking on dry runway at touchdown. The assumptions for the reverse thrust ground roll were: reverse thrust and wheel braking available on wheel touchdown, dry runway, and reverse thrust available to zero velocity. With these assumptions, the maximum performance ground roll can be reduced from about $762 \mathrm{~m}(2500 \mathrm{ft})$ to $244 \mathrm{~m}(800 \mathrm{ft})$. Of course, dispersion, wet runways, and a delay in application of full reverse thrust or reverse thrust cutoff at velocities greater than zero will considerably increase the landing ground roll.

\section{CONCLUDING REMARKS}

NASA Langley Research Center has conducted wind-tunnel investigations in the 4- by 7-Meter Tunnel of several fighter configurations to determine the effects of both thrust vectoring and spanwise blowing. These investigations included: a NASA powered wing-canard configuration which used two-dimensional vectored nozzles at the wing trailing edge; a General Dynamics powered vectored-engine-over wing configuration which used two-dimensional main nozzles along with spanwise blowing on the wing upper surface over deflected flaps, and a Boeing supersonic cruise configuration which used two-dimensional vectoring nozzles below the wing along with a direct lift nose jet for trim.

An analysis of previous wind-tunnel data has led to the conclusion that, in general, the thrust-induced effects from main nozzles on the longitudinal aerodynamics of fighter configurations are small compared to direct thrust effects. However, induced effects from spanwise blowing can be significantly greater. obtaining longitudinal trim can be extremely difficult when deflected thrust is used in an effort to take advantage of either direct or thrust-induced effects to increase lift coefficient. Numerous combinations of lift and drag can be obtained using vectored thrust, but longitudinal trim is difficult to achieve. One effective trim method was demonstrated using a forward fuselage mounted jet which produces a lift force equal to about 10 to 15 percent of the total thrust.

A concept of using spanwise blowing on the trailing-edge flap has indicated that a fairly significant lift increment is possible when an under-the-wing blowing cascade is used in conjunction with large flap deflections. This lift 
increment is accompanied by the large nose-down pitching moments typical of vectored thrust concepts.

An investigation of the effects of reverse thrust on the low-speed aerodynamics of an F-15 configuration indicates that a rotating vane concept will provide the partial thrust required for approach while maintaining military power settings, and effective reverse thrust for a significant reduction in ground roll. It appears that in the angle-of-attack range required for approach, the F-15 with the rotating vane thrust reverser maintains adequate rudder and horizontal tail power as well as directional stability. 
REFERENCES

1. Paulson, J. W., Jr.; and Thomas, J. L.: Summary of Low-speed Longitudinal Aerodynamics of Two Powered Close-Coupled Wing-Canard Fighter Configurations. NASA TP-1535, 1.979.

2. Paulson, J. W., Jr.; and Thomas, J. L.: Effect of Twist and Camber On the Low-Speed Aerodynamic Characteristics of a Powered Close-Coupled Wing-Canard Configuration. NASA TM-78722, 1978.

3. Paulson, J. W., Jr.; Thomas, J. L.; and Winston, M. M.: Transition Aerodynamics for Close-Coupled Wing-Canard Configuration. AIAA Paper 79-0336, January 1979.

4. Paulson, J. W., Jr.: An Analysis of Thrust-Induced Effects on the Longitudinal Aerodynamics of STOL Fighter Configurations. AIAA Paper 80-1879, August 1980 .

5. Paulson, J. W., Jr.: Tactical Aircraft Research and Technology, ThrustAerodynamics of STOL Fighter Configurations. NASA CP-2162, Tactical Aircraft Research and Technology, Part 2, vol. 1, October. 21-23, 1980.

6. Whitten, P. D.: An Experimental Investigation of a Vectored-Engine-Over-Wing Powered-Lift Concept. U.S. Air Force Flight Dynamics Laboratory Technical Report AFFDL-TR-76-92, Vol. II-High Angle of Attack and STOL Tests, March 1978.

7. Leavitt, L. D.; and Yip, L. P.: Effects of Spanwise Nozzle Geometry and Location on the Longitudinal Aerodynamic Characteristics of a VectoredEngine-Over-Wing Configuration at Subsonic Speeds. NASA TP-1215, 1978.

8. Whitten, P. D.; and Howell, G. A.: Investigations of the VEO-Wing Concept in Air-To-Ground Role. U.S. Air Force Flight Dynamics Laboratory Technical Report AFFDL-TR-79-3031, March 1979.

9. Stumpfl, S. C.: Vectored-Engine-Over-Wing Concept Development. Proceedings V/STOL Aircraft Aerodynamics, Vol. II. Naval Postgraduate School, Monterey, California, May 1979, pp. 850:

10. Whitten, P. D.; and Howell, G. A.: Data Report for Low-Speed Test of the 0.108-Scale Vectored-Engine-Over-Wing Powered-Lift Research Mode1. Volume I-Force Data. General Dynamics/Ft. Worth Division Report FZA-501-Vol. 1, September 1979. 


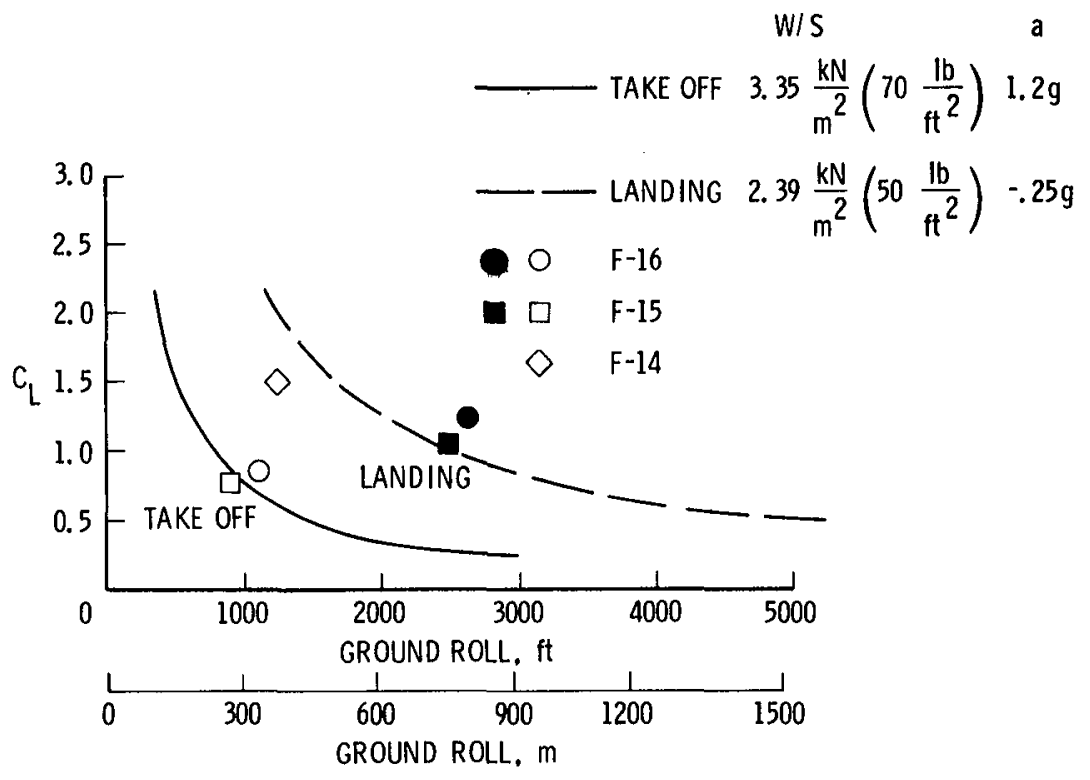

Fig. 1. Fighter takeoff and landing ground rolls.

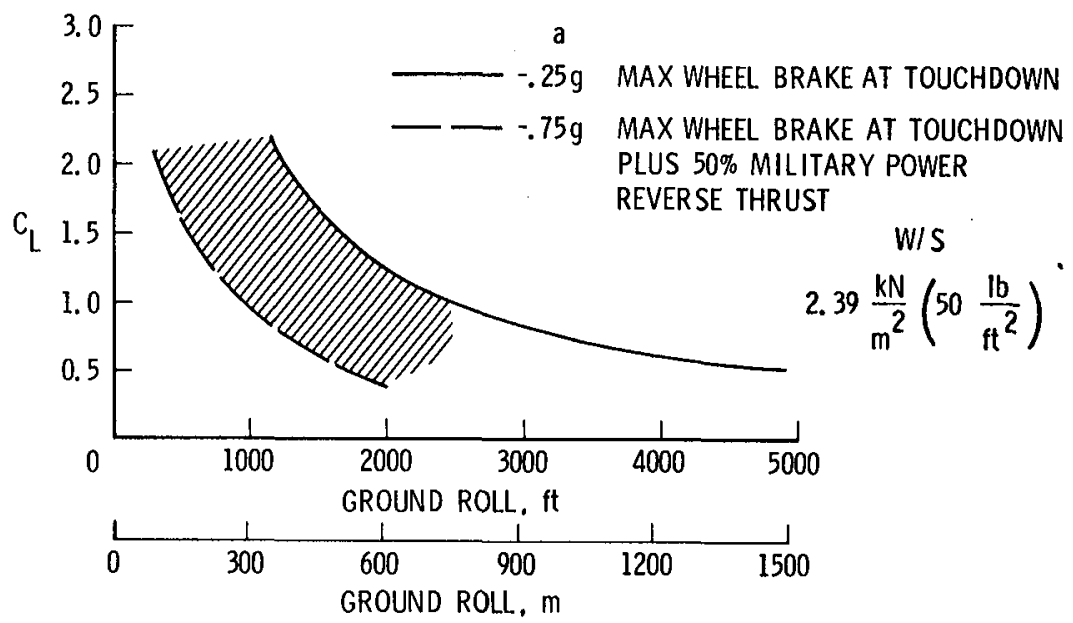

Fig. 2. Effect of lift coefficient and reverse thrust on landing ground roll. 


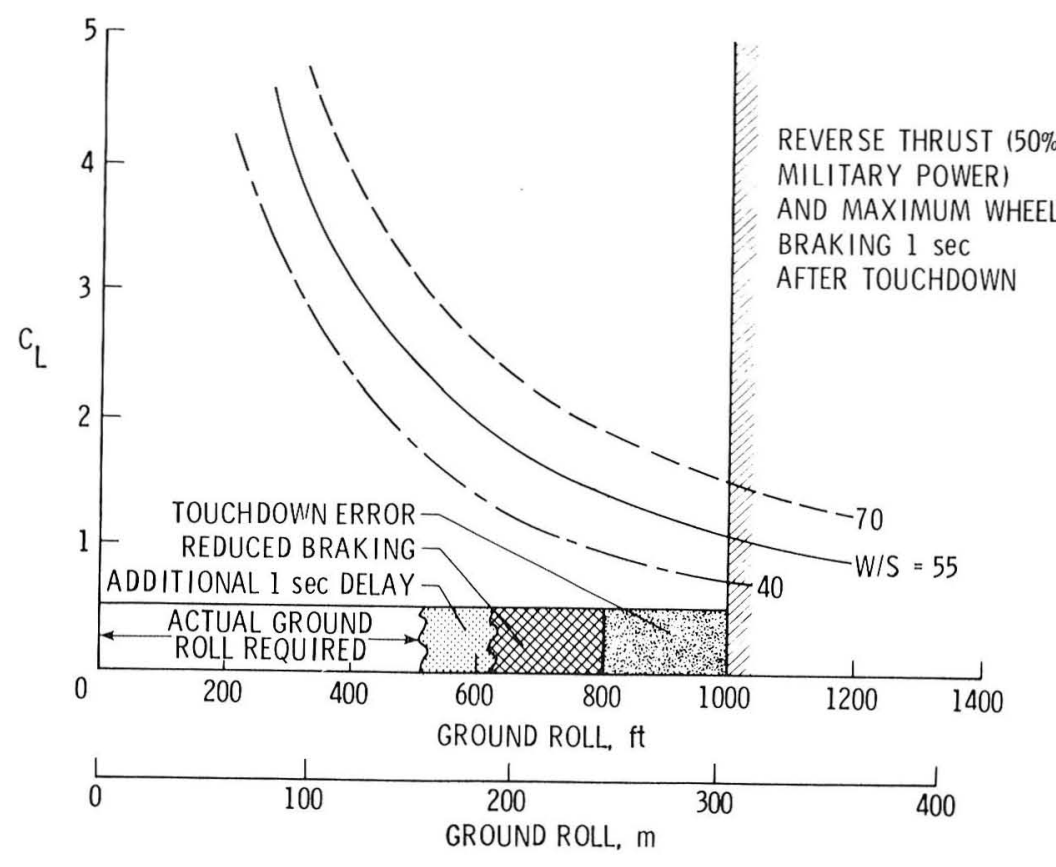

Fig. 3. Approach lift coefficient versus landing ground roll for fighter aircraft.

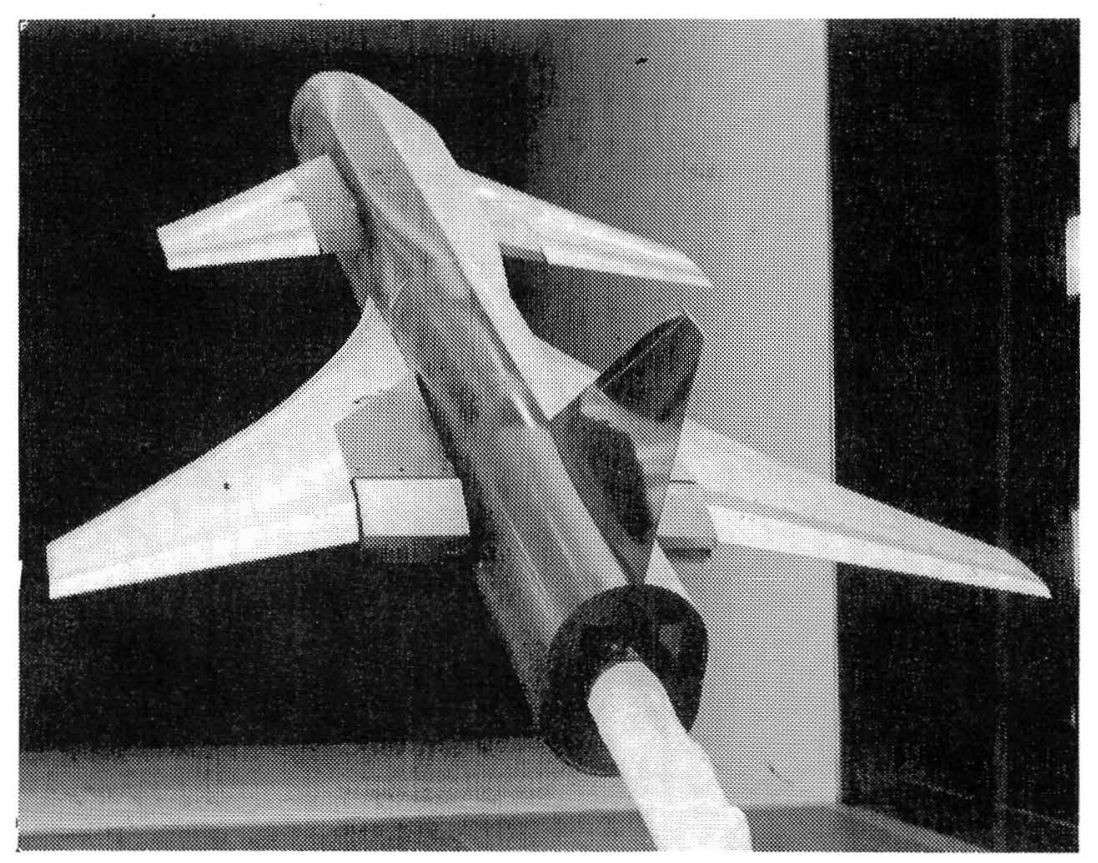

Fig. 4. NASA powered wing-canard fighter configuration installed in the $4-$ by 7 -Meter Tunne1. 


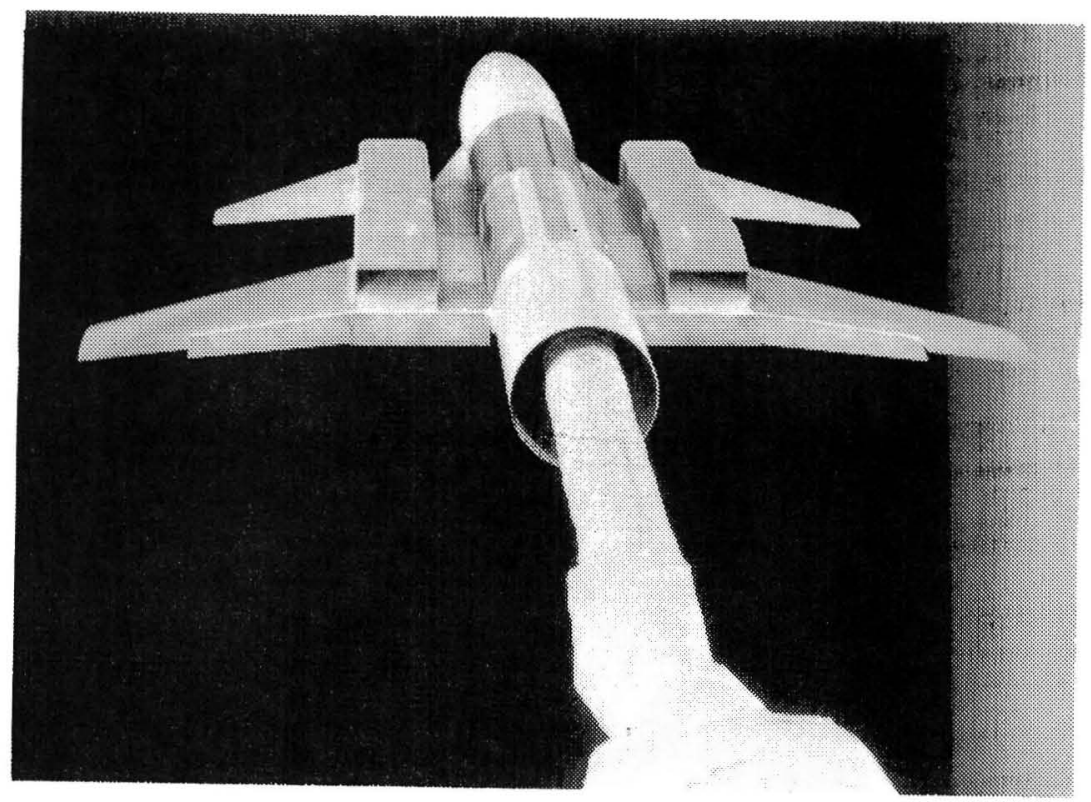

Fig. 5. General Dynamics powered VEO wing configuration in 4- by 7-Meter Tunnel.

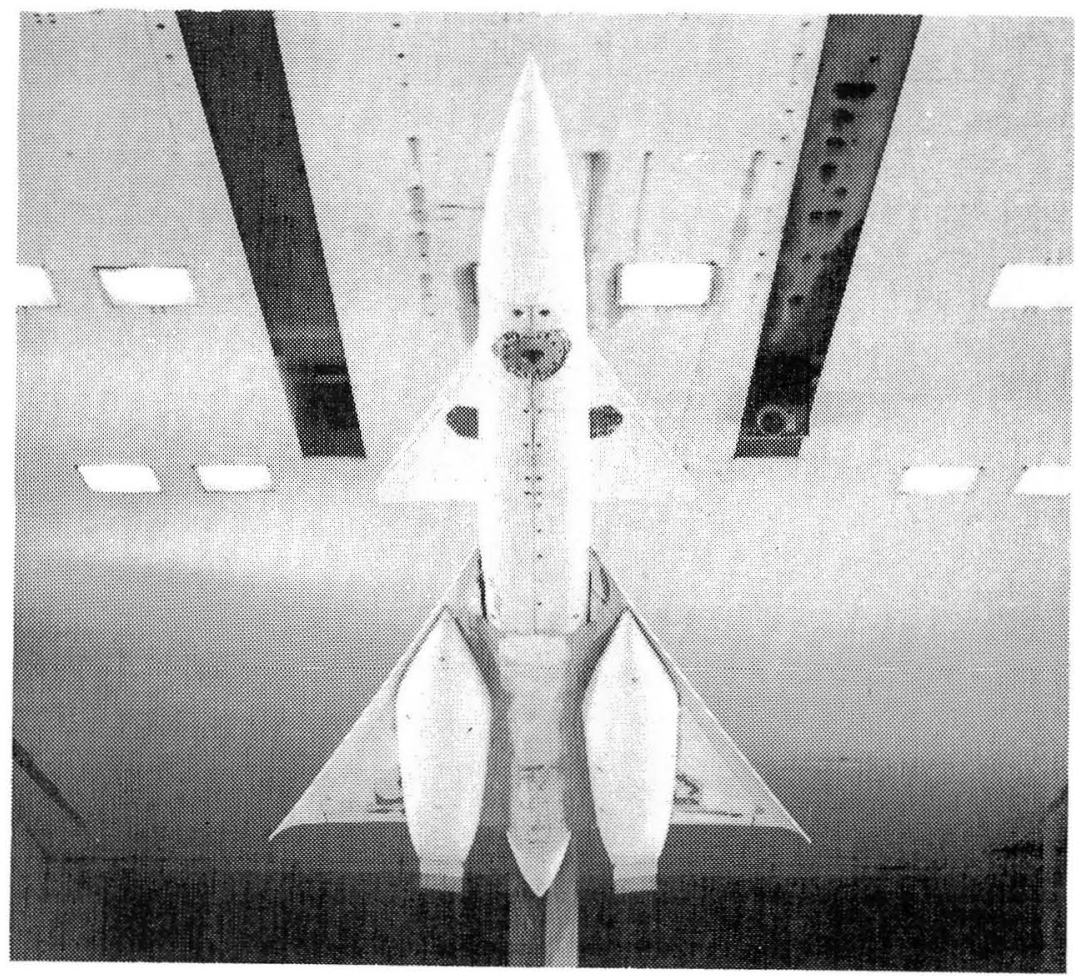

Fig. 6. Boeing powered sueprcruiser configuration with nose jet installed in 4- by 7-Meter Tunnel. 

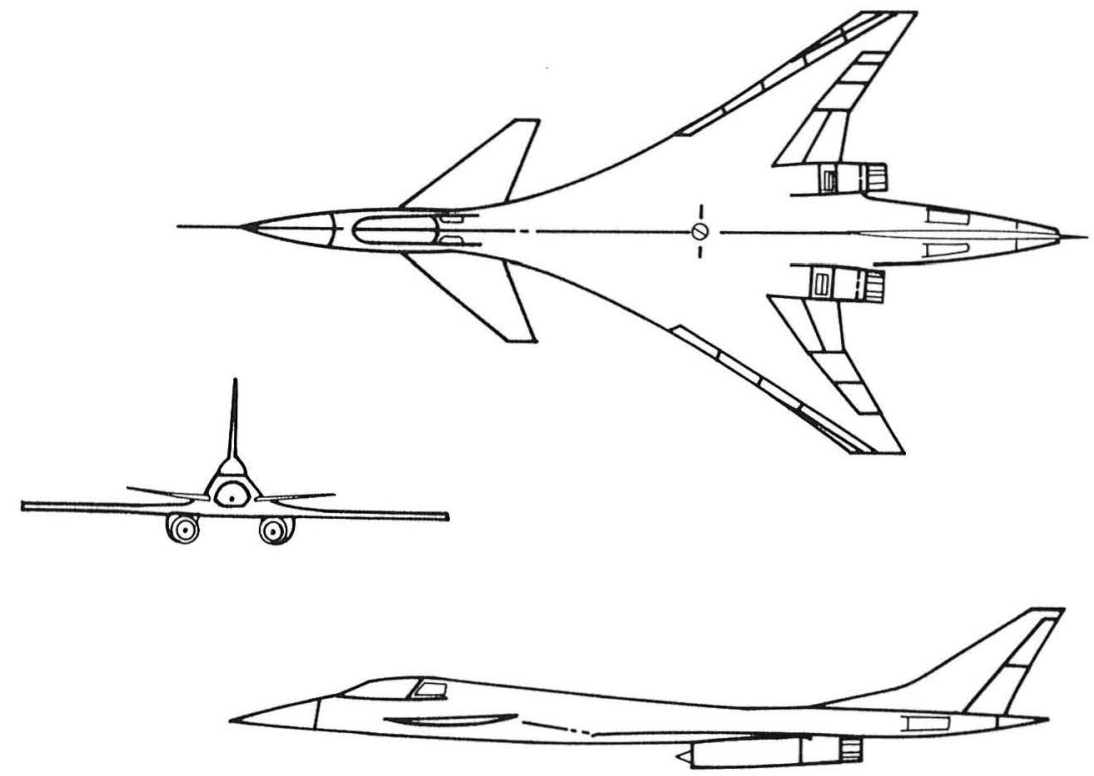

Fig. 7. Grumman advanced fighter configuration.

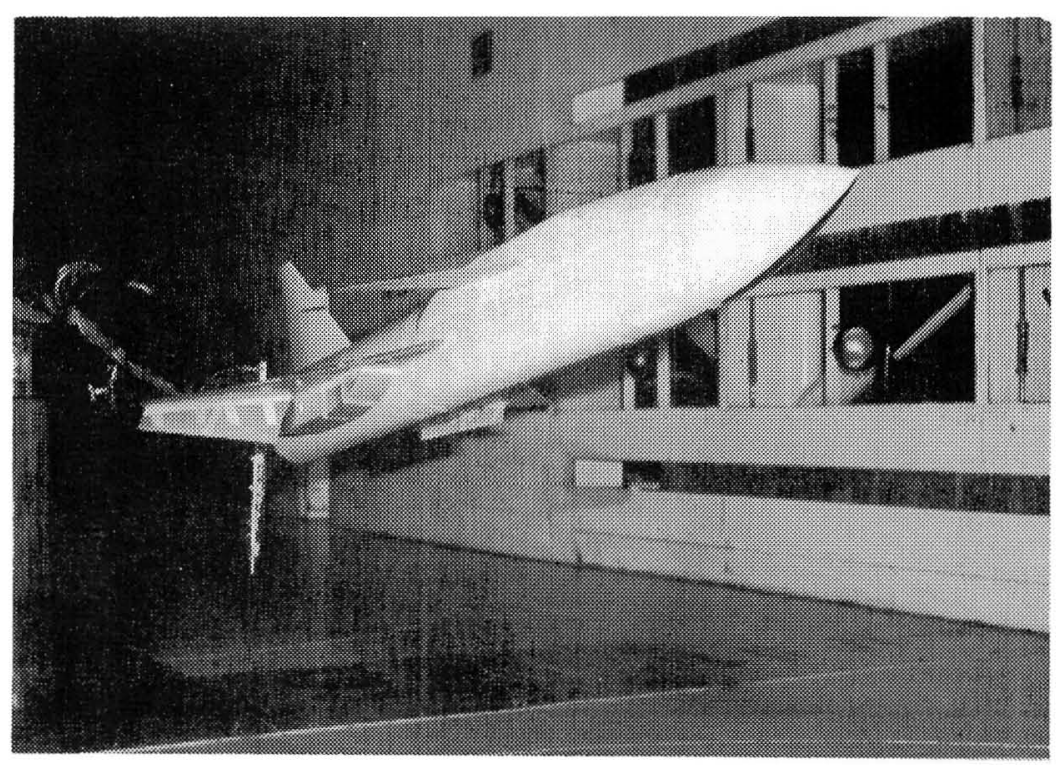

Fig. 8. Modified NASA wing-canard fighter mode1 installed in $4-$ by 7 -Meter Tunnel. 


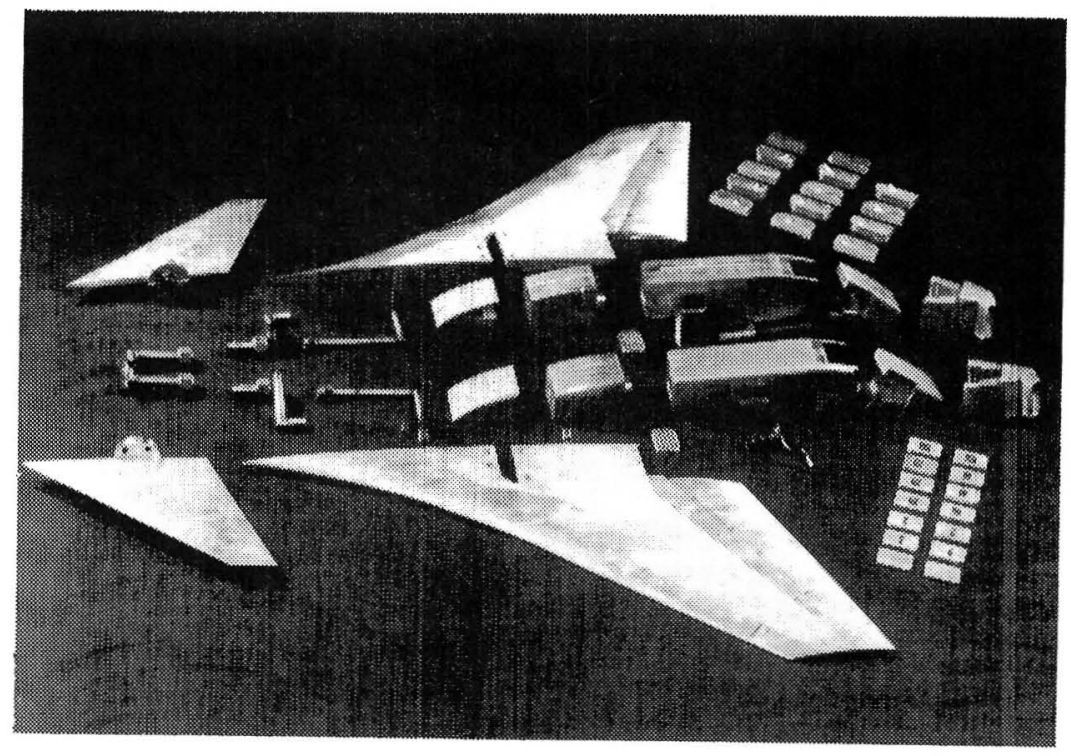

Fig. 9. New model parts for NASA wing-canard fighter model.

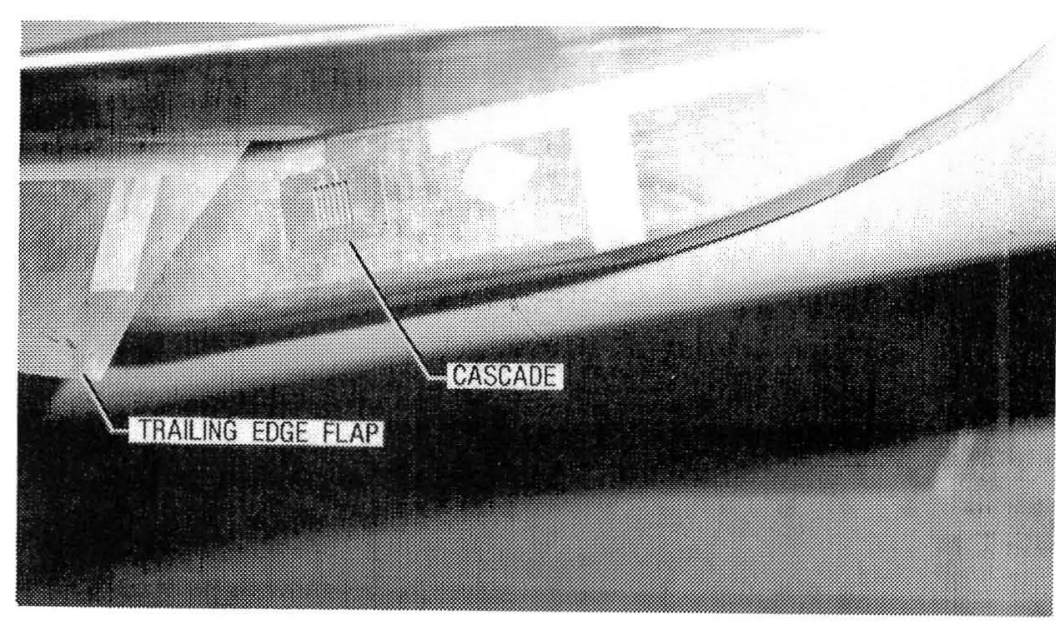

Fig. 10. Below wing cascade on nacelle of modified NASA wing-canard fighter mode1. 


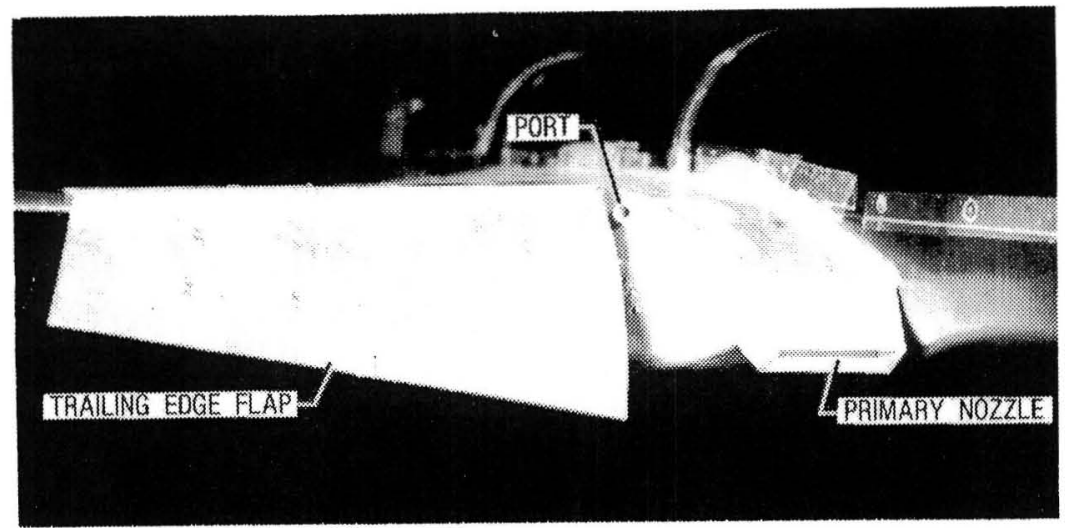

Fig. 11. Above wing port on modified NASA wing-canard fighter model.

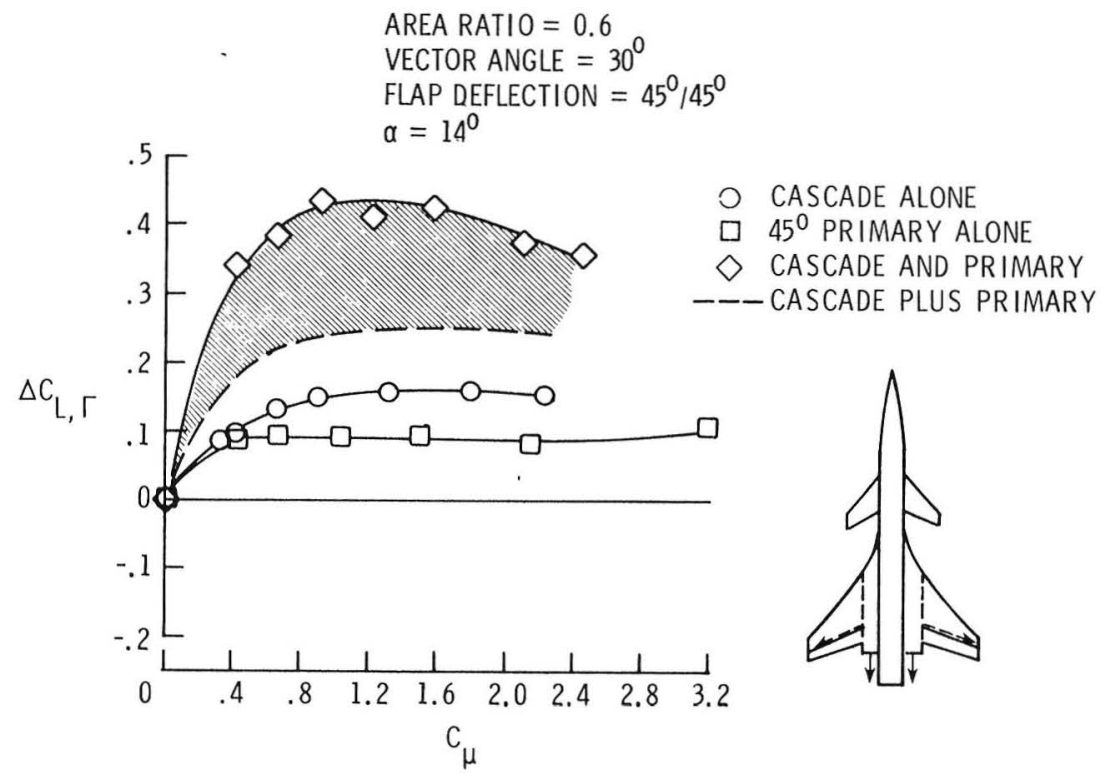

Fig. 12. Induced lift for cascade blowing paralle1 to flap hinge line. 


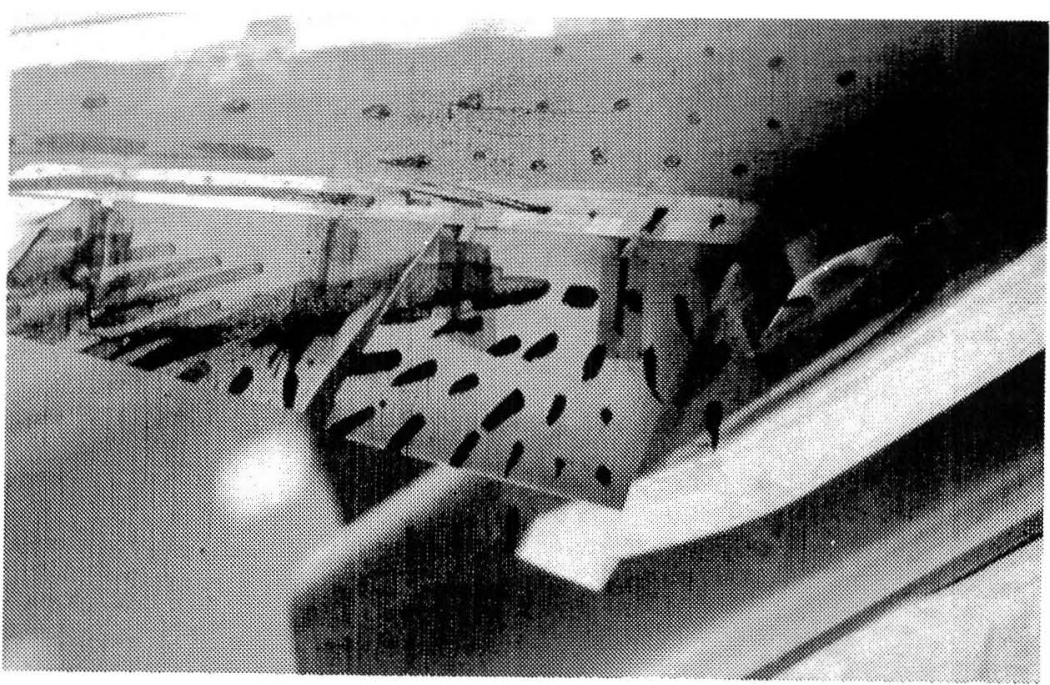

Fig. 13. 0il flow with cascade blowing parallel to flap hinge line.

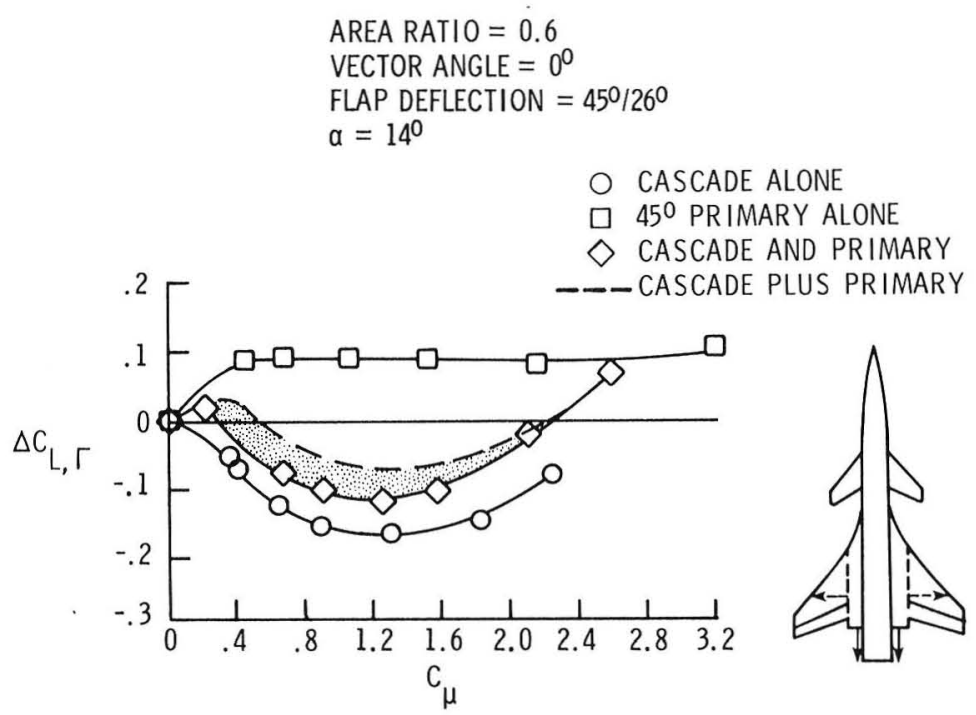

Fig. 14. Induced lift with cascade blowing perpendicular to body centerline. 


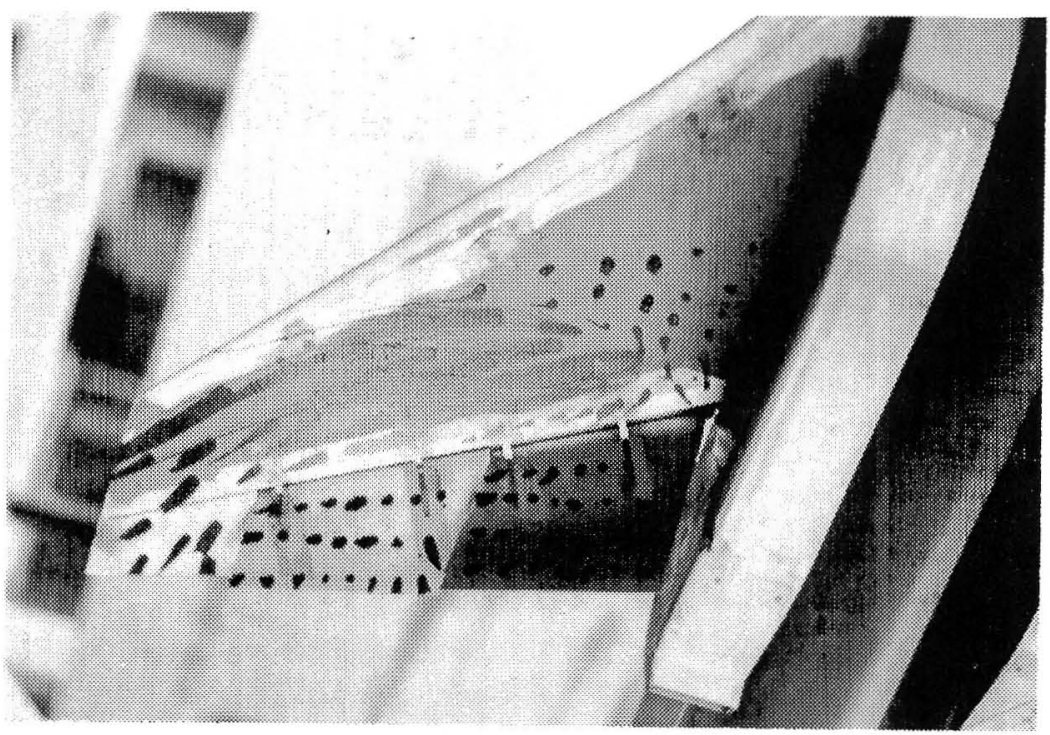

Fig. 15. Oil flow with cascade blowing perpendicular to body centerline.

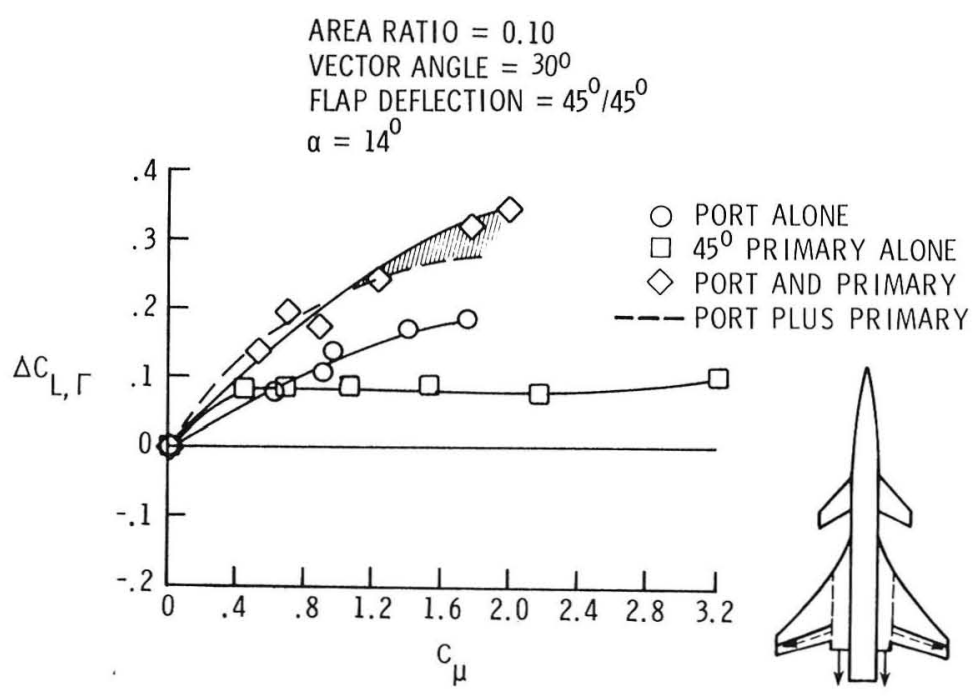

Fig. 16. Induced lift for port blowing parallel to flap hinge line. 


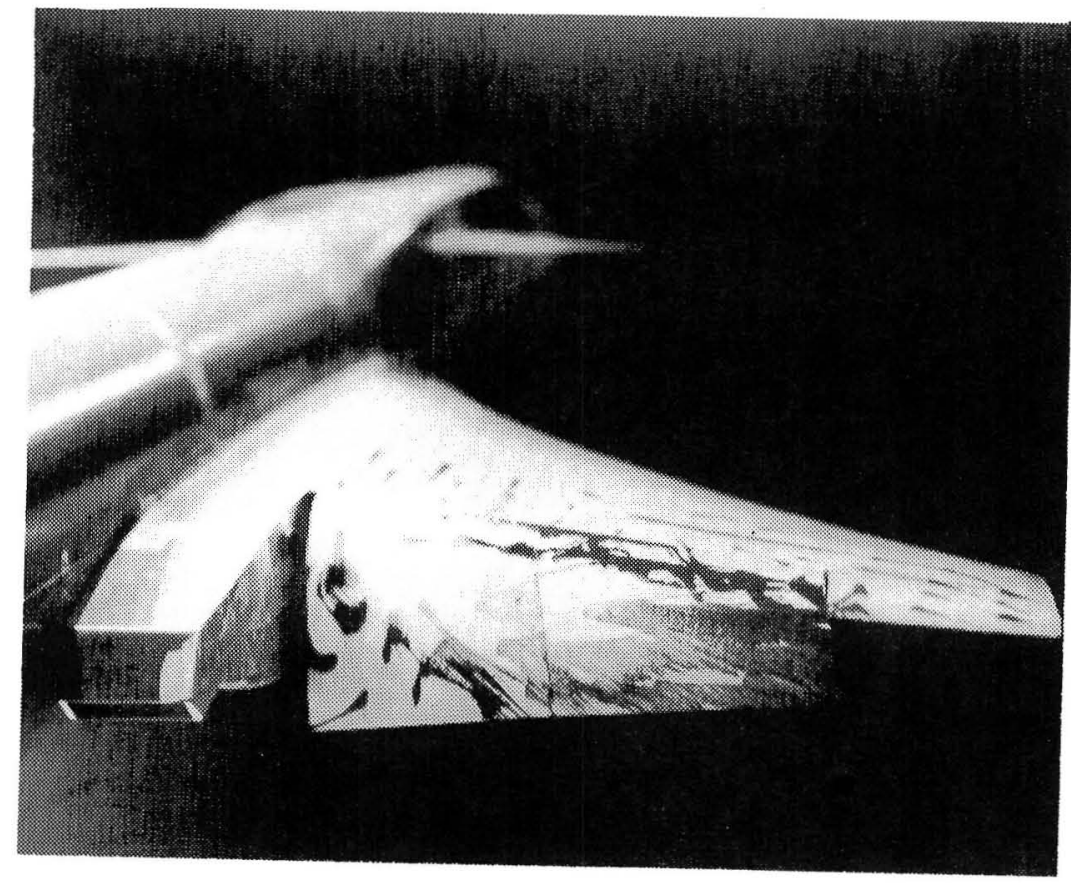

Fig. 17. Oil flow with port blowing parallel to flap hinge line.
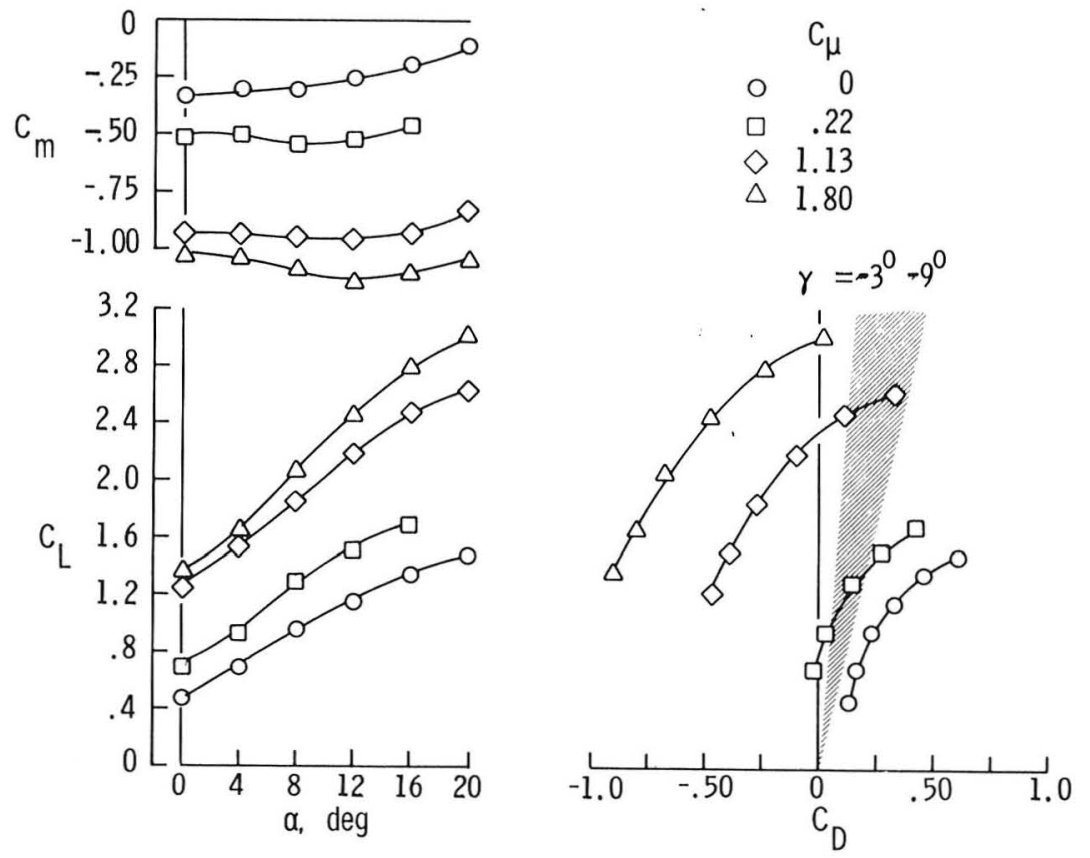

Fig. 18. Longitudinal aerodynamics with cascade blowing parallel to flap hinge line, primary nozzles deflected $45^{\circ}$ and flaps deflected $45^{\circ} / 45^{\circ}$. 


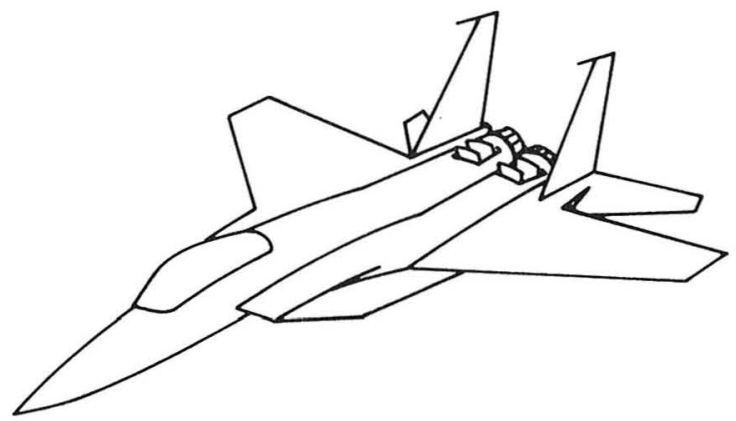

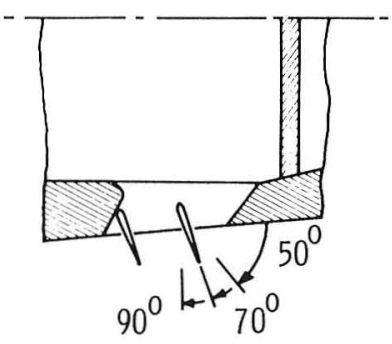

APPROACH

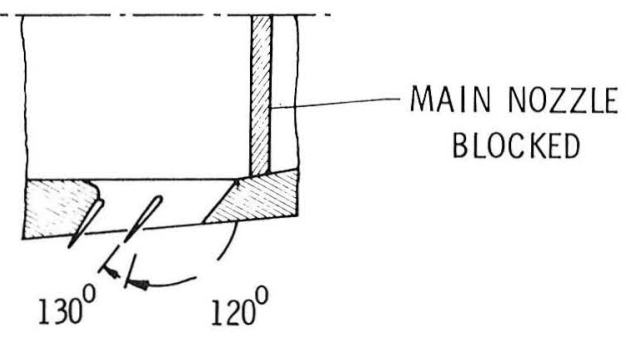

GROUND ROLL

Fig. 19. Rotating vane thrust reverser concept.

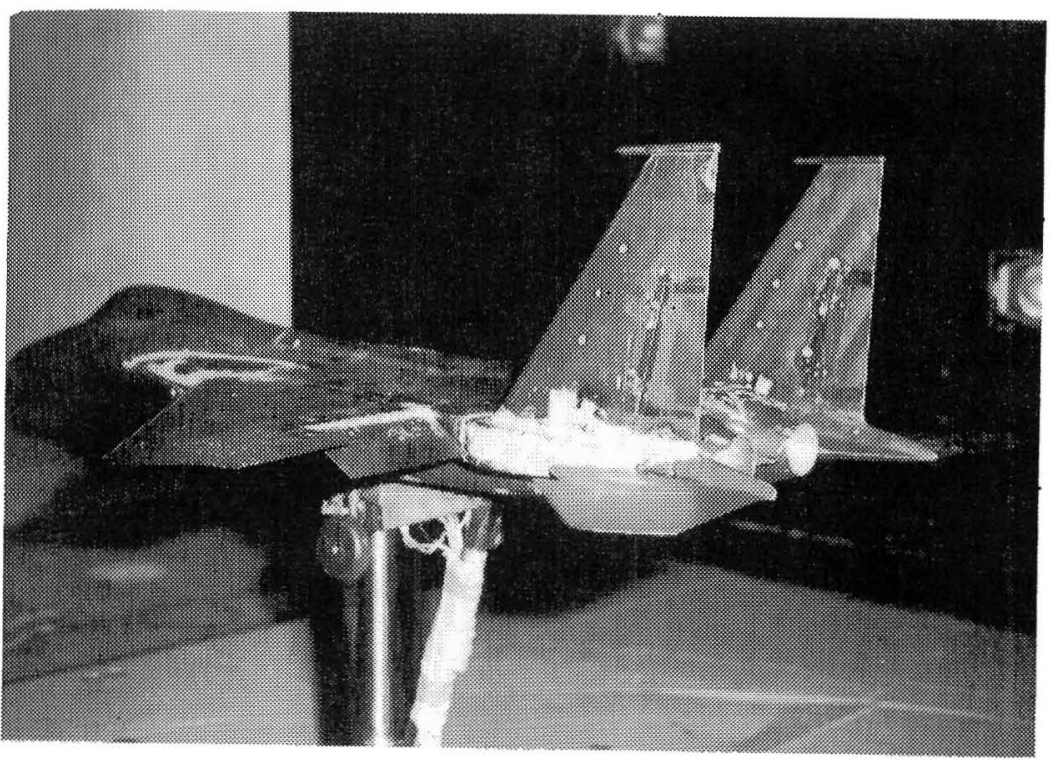

Fig. 20. MACAIR F-15 model installed in the 4- by 7-Meter Tunne1. 


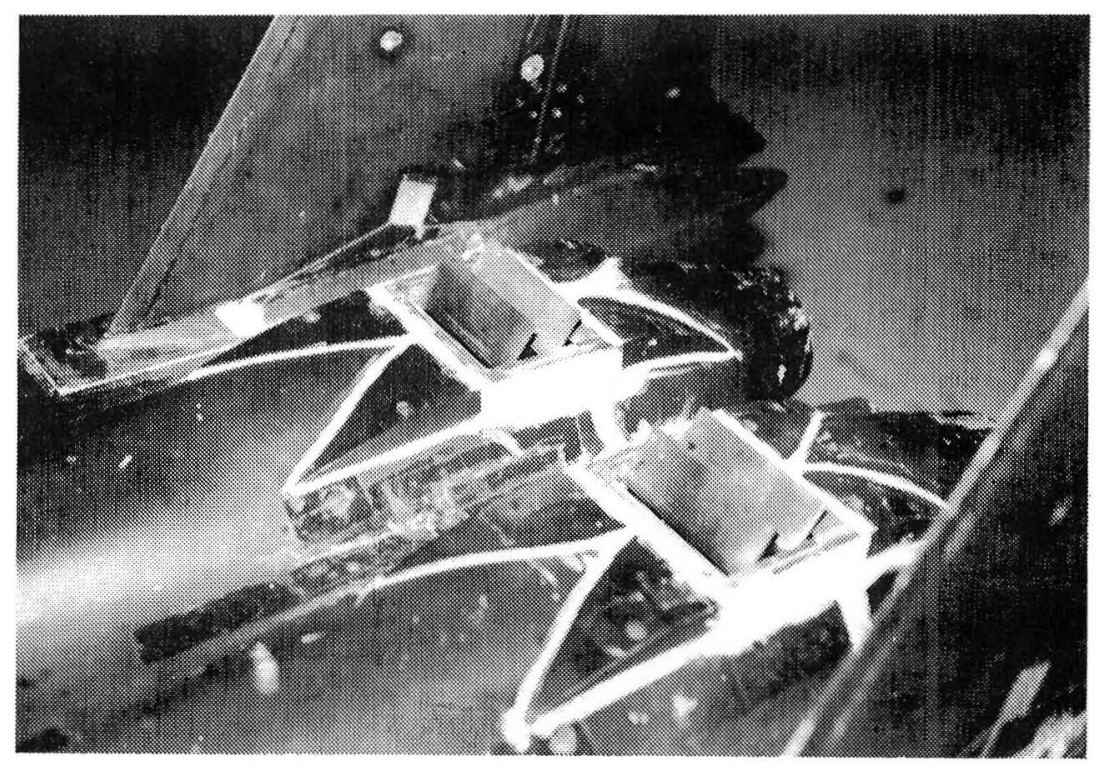

Fig. 21. Closeup of rotating vane thrust reverser concept.
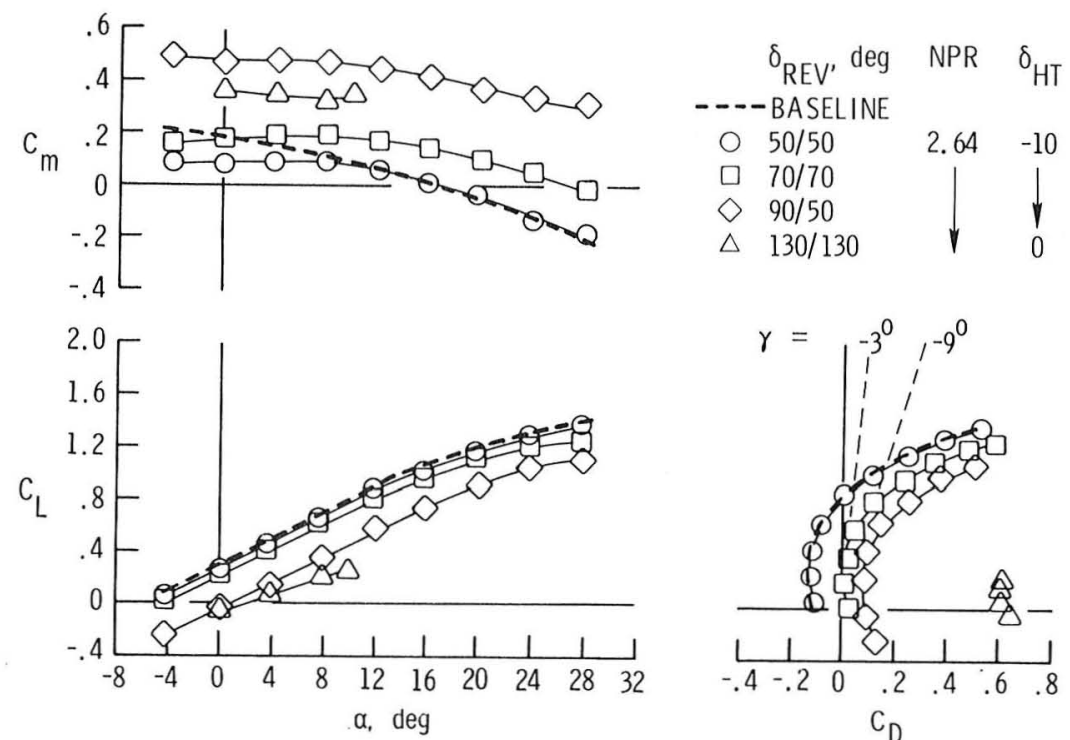

Fig. 22. Longitudinal aerodynamics of F-15 mode1 with rotating vane thrust reversers at several vector angles. 


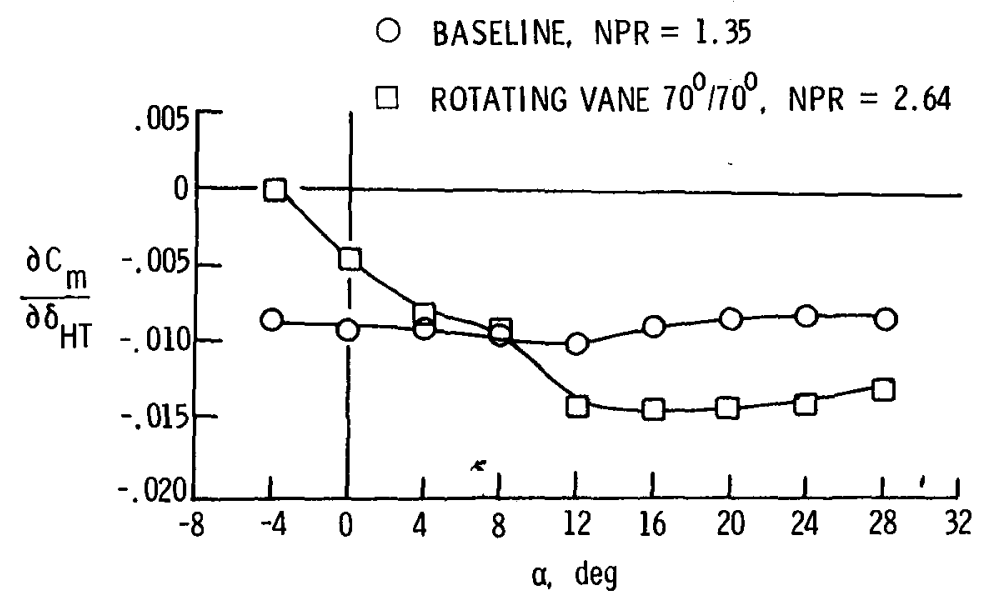

Fig. 23. Horizontal-tal1 power for F-15 mode1 with and without partial thrust reversing.
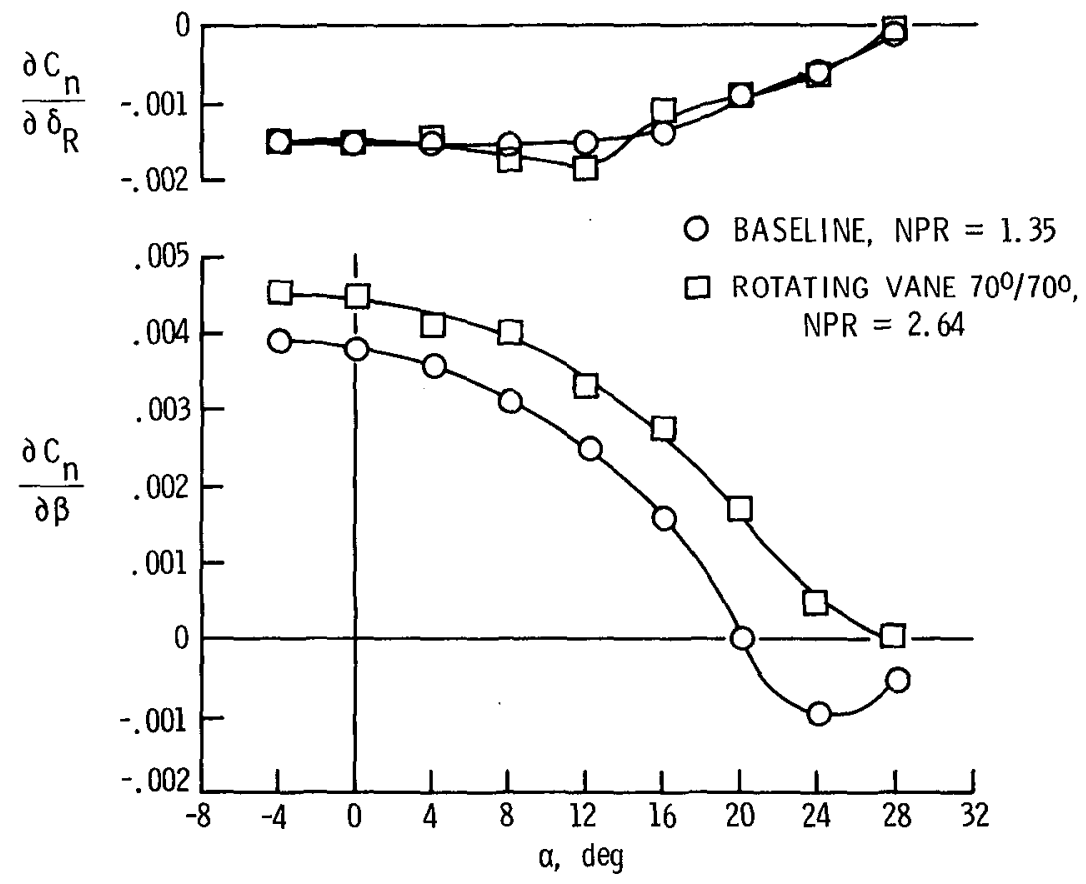

Fig. 24. Directional stability and rudder power for F-15 model with and without partial thrust reversing. 


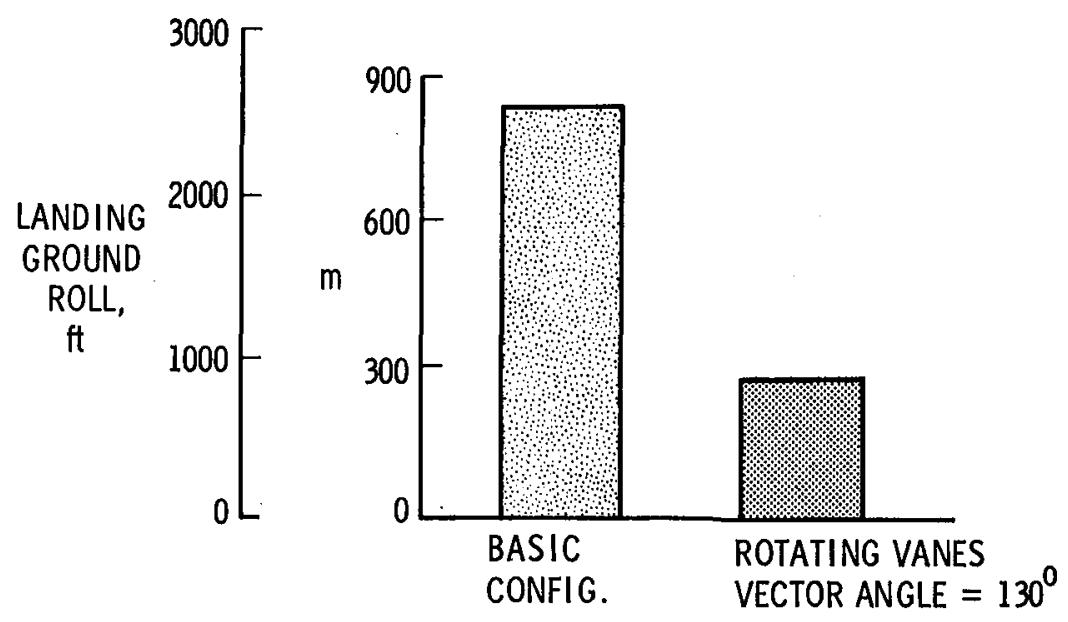

F1g. 25. Estimated minimum ground roll for F-15 with and without thrust reversing. 


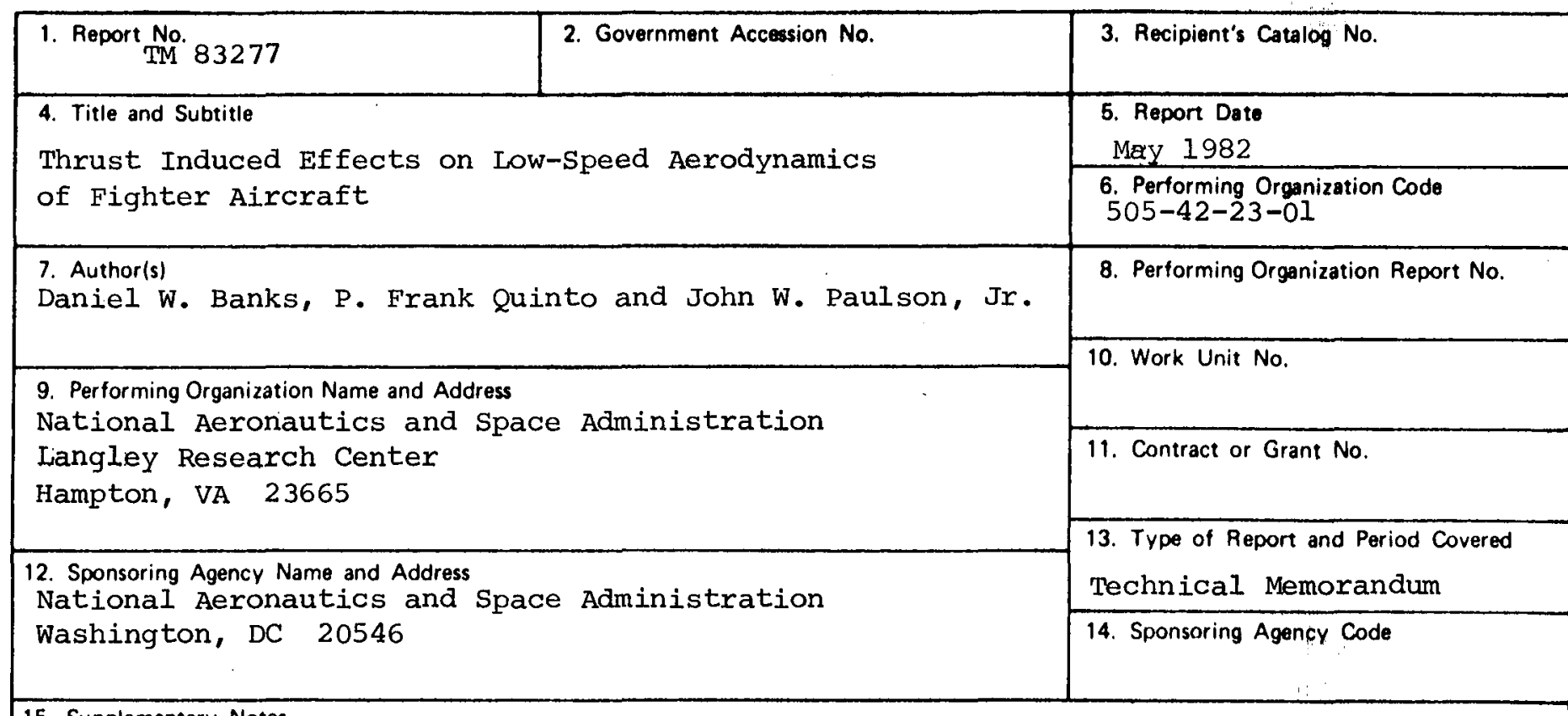

15. Supplementary Notes

16. Abstract

A brief review of takeoff and landing requirements for the next generation of fighter aircraft indicates that improvement in lift performance and thrust reversing capability will be needed if Short Takeoff and Landing (STOL) operations are to be feasible. NASA Langley has conducted wind-tunnel investigations of several fighter configurations to determine the effects of both thrust vectoring and spanwise blowing. Since these results have been published elsewhere, these findings are only reviewed briefly in this paper. A recent joint NASA/Grumman Aerospace Corporation/U.s. Air Force Wright Aeronautical Laboratory wind-tunnel investigation was conducted to examine the effects of spanwise blowing on the trailing-edge flap system. This application contrasts with the more familiar method of spanwise blowing near the wing leading edge. Another joint program among NASA/McDonnell Aircraft Company/U.S. Air Force Wright Aeronautical Laboratory investigated the effects of reverse thrust on the lowspeed aerodynamics of an F-15 configuration. The F-15 model was fitted with a rotating vane thrust reverser concept which could simulate both in-flight reversing for approach and landing or full reversing for ground roll reduction. The significant results of these two joint programs are reported in this paper.

17. Key Words (Suggested by Author(s))

thrust-induced effect.s

spanwise blowing

vectored thrust

low-speed fighter aerodynamics
18. Distribution Statement

Unclassified-Unlimited

Subject Category 02
19. Security Classif. (of this report)

Unclassified

20. Security Classif. (of this page)
Unclassified

\begin{tabular}{|r|r|}
\hline 21. No. of Pages & $\begin{array}{r}\text { 22. Price } \\
24\end{array}$ \\
$\mathrm{AO} 2$
\end{tabular}



W

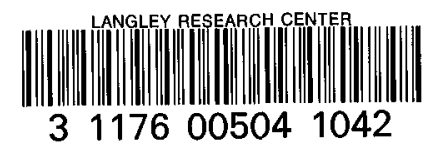

